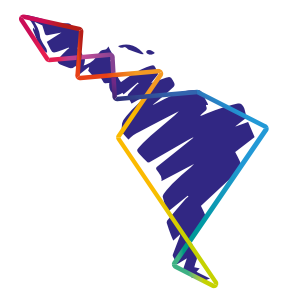

\title{
Perspectivas en la protección no jurisdiccional del derecho humano a la vivienda en México
}

\author{
Perspectives on the non-jurisdictional \\ protection of the human right to housing \\ in Mexico
}

\section{Perspectivas sobre a proteção não jurisdicional do direito humano à moradia no México}

\author{
Mayra Patricia Venegas Agüeros ${ }^{1}$ \\ Mauro Pérez Bravo²
}

\begin{abstract}
Resumen
En el presente artículo, se abordará el papel que los organismos públicos protectores de derechos humanos han realizado en lo que se refiere a la protección del derecho a la vivienda. Desde nuestro punto de vista, es necesario reforzar todos los medios que resguarden tal derecho; en este caso, hablamos de la protección no jurisdiccional realizada por los organismos mencionados. Este ensayo retoma los principales alcances y logros que han destacado en el tema, de acuerdo con los estándares constitucionales y convencionales que sean pertinentes. Lo anterior, con el propósito de que, al final, podamos hacer un balance sobre lo que implica una protección más efectiva de los derechos humanos, desde el ámbito no jurisdiccional, según los retos que implica el derecho a la vivienda para personas en situación de vulnerabilidad.
\end{abstract}

Palabras clave: derechos humanos, vivienda, protección no jurisdiccional, derechos sociales.

1 Abogada, Universidad Autónoma de Querétaro, mexicana. Correo electrónico: mayck1991@hotmail.com ORCID: https://orcid.org/0000-0001-5907-0722

2 Doctorando en Derecho, Universidad Nacional Autónoma de México.

Correo electrónico: mauro050@yahoo.com.mx. ORCID: https://orcid.org/0000-0002-9303-4730 


\begin{abstract}
This article will address the role that Public Organizations Protecting Human Rights have performed in relation to the protection of the right to housing. From our perspective, it is necessary to reinforce all the means of protection of the human right to housing, in this case, in regards to the non-jurisdictional protection carried out by Public Organizations Protecting Human Rights. In the present essay we will touch on the main scopes and achievements that have stood out in the protection of the human right to housing, in accordance with the constitutional and conventional standards that are pertinent to the case. So that in the end, we can take stock of what a more effective protection of human rights implies, from the non-jurisdictional sphere, in accordance with the challenges that the right to housing implies for people in vulnerable situations.
\end{abstract}

Keywords: Human rights; Housing; Non-jurisdictional protection; Social rights.

\title{
Resumo
}

Este artigo tratará do papel que as Organizações Públicas de Proteção dos Direitos Humanos têm desempenhado em relação à proteção do direito à moradia. Do nosso ponto de vista, é necessário reforçar todos os meios de tutela do direito humano à moradia, neste caso, estamos a falar da tutela não jurisdicional exercida por Organismos Públicos de Defesa dos Direitos Humanos. Neste ensaio, você retornará às principais conquistas e conquistas que se destacaram na proteção do direito humano à moradia, de acordo com as normas constitucionais e convencionais pertinentes ao caso. Para que, ao final, possamos fazer um balanço do que implica uma proteção mais efetiva dos direitos humanos, desde a esfera não jurisdicional, de acordo com os desafios que o direito à moradia implica para as pessoas em situação de vulnerabilidade.

Palavras-chave: Direitos humanos; Moradia; Proteção não jurisdicional; Direitos sociais.

\section{Introducción}

En el presente trabajo abordaremos el estudio sobre la protección no jurisdiccional del derecho humano a la vivienda en el sistema jurídico mexicano. Desarrollaremos algunos rasgos que consideramos importantes de los organismos protectores de derechos humanos, concretamente, de la Comisión Nacional de los Derechos Humanos (CNDH), como entidad nacional autónoma con la encomienda de defender, proteger y promover los derechos humanos.

Comenzaremos por exponer brevemente la teoría de los derechos humanos y su evolución, para centrarnos luego en la exposición de los derechos, sociales y culturales, entre los cuales ubicamos el derecho humano a la vivienda.

Una vez realizado lo anterior, pasaremos al desarrollo doctrinal y legislativo del derecho humano a la vivienda; analizaremos las dos principales instituciones del 
sistema gubernamental de México encargadas de promover tal derecho: 1) Instituto del Fondo Nacional de la Vivienda de los Trabajadores y 2) Fondo de la Vivienda del Instituto de Seguridad y Servicios Sociales de los Trabajadores del Estado.

Posteriormente, nos adentraremos en el estudio de la protección no jurisdiccional que ha realizado la Comisión Nacional de los Derechos Humanos (CNDH) en relación con el derecho humano a la vivienda. En este apartado, podremos profundizar el examen y la reflexión sobre las recomendaciones y acciones que ha emitido la $\mathrm{CNDH}$ en cuanto al derecho especificado y cuáles han sido los principales aportes/beneficios para las víctimas de violaciones a derechos humanos por parte del Instituto del Fondo Nacional de la Vivienda de los Trabajadores, así como del Fondo de la Vivienda del Instituto de Seguridad y Servicios Sociales de los Trabajadores del Estado.

Nuestro objetivo es exponer el papel que desempeñan los organismos públicos defensores de derechos humanos en torno a la protección del derecho humano a la vivienda, para que, de esta manera, podamos conocer la importancia de instituciones como la CNDH, así como de los mecanismos a los que pueden tener acceso las personas que han sido víctimas de violaciones a sus derechos humanos, por acciones u omisiones de las autoridades encargadas de ejecutar las políticas públicas en materia del derecho humano a la vivienda.

\section{Los derechos humanos y los derechos económicos, sociales y culturales (DESC)}

Antes de abordar el estudio del derecho a la vivienda en el contexto de los DESC, en esta primera parte desarrollaremos brevemente dos de las principales tradiciones jurídicas sobre derechos humanos: iusnaturalismo y positivismo. Lo anterior, a fin de contar con un panorama básico sobre los derechos humanos, para después adentrarnos en el contexto de los derechos económicos, sociales y culturales.

En la antigüedad, filósofos y pensadores tanto políticos como jurídicos se preguntaron si el derecho provenía de la ley o de la naturaleza. Los que se afilian a la segunda postura componen la corriente doctrinaria denominada iusnaturalismo, en la cual los juristas han sostenido la creencia de que el derecho debe tener una base en lo más íntimo de la naturaleza del ser humano como ser individual o colectivo (Ríos, 1996).

El iusnaturalismo comprende todas las llamadas doctrinas del derecho natural, por lo general, encontramos a las escuelas moderna, clásica, racionalista, historicista, contemporánea, formalista y neotomista. 
A la par del iusnaturalismo, tenemos la visión del iuspositivismo, en el cual el derecho proviene de la ley y los procedimientos adecuados para su creación; por ello, todo el derecho como ciencia o estudio se ve centrado en la regla que está escrita. En esta perspectiva, no existe otro derecho que el que está en la ley. Se relaciona profundamente el derecho positivo con el principio de legalidad, ya que el derecho está contenido en una norma y consta por escrito, lo que le proporciona un carácter oficial, democrático y obligatorio (Rodríguez Moreno, 2011).

Entonces, las dos grandes tradiciones que tenemos sobre el derecho en concreto son: iusnaturalismo y iuspositivismo, ¿dónde ubicar entonces los derechos humanos? Desde nuestra visión, estos constituyen un nuevo paradigma en la comprensión de los derechos del ser humano. Se involucran ya no solo en la vida estrictamente jurídica de la sociedad y de los humanos, sino que implican diversos ámbitos: sociales, culturales, económicos, éticos y políticos, por decir algunos.

Dada esta complejidad, no es suficiente restringir su comprensión a la esfera meramente legal, al derecho positivo, entendido este como el meramente escrito: "Si el derecho reviste estructura normativa, pero no es solamente un sistema de normas, ¿no podemos sostener que la positividad de derecho consiste en 'poner' normas en el mundo jurídico?" (Hidalgo Bonilla, 2006, p. 179). De acuerdo con este planteamiento, podremos apreciar que el derecho no es solo la ley en sí misma, sino que involucra muchas cuestiones como las señaladas en el párrafo que antecede.

Consideramos que los derechos humanos implican mucho más que el mero ordenamiento legal, ya que, al hablar de ellos, involucramos temas complejos que no siempre pueden resolverse atendiendo única y exclusivamente la normatividad establecida, tales como la dignidad, libertad o vida en sociedad. Para una construcción más completa y adecuada en el asunto de los derechos humanos, al igual que del derecho en general, es conveniente que se tomen en cuenta tanto los aspectos éticos y morales como los prácticos y concretos (entre estos, el derecho positivo).

De tal modo, podemos enunciar que los derechos humanos son:

el conjunto de filosofías sociales, políticas, económicas, culturales, religiosas, aspiraciones éticas, de justicia, de seguridad, de equidad, juicios de valor, etc., que se encuentran consagrados en la Constitución Federal, y en los Tratados, Convenios, Convenciones, pactos y otros documentos internacionales, que México a incorporado (sic) a su derecho interno, conforme al artículo 133 Constitucional (Herrera Ortiz, 2003, p. 22). 
Así pues, los derechos humanos pudiesen concebirse como el producto de la convivencia social y, con el paso del tiempo, van incluyendo el estudio sobre dignidad del ser humano, así como van elaborando valores y garantías para lograr una vida plena, de los grupos y la sociedad en su conjunto (Quintana, 1998, p. 29).

La idea jurídica de los derechos humanos se forma con el reconocimiento, en la misma norma jurídica, de aquellos axiomas, valores y atributos generados a partir del análisis filosófico, ético y político de aquello que es la persona humana; es decir, no podemos dar un significado jurídico sobre derechos humanos, sin hacer un análisis complementario, tomando en cuenta los diferentes ámbitos en los cuales se les tiene presente.

En México, el 10 de junio de 2011, se publicó, en el Diario Oficial de la Federación, el decreto por el que se modificó la denominación del capítulo I del título primero y se corrigieron diversos artículos de la Constitución Política de los Estados Unidos Mexicanos, lo que fue conocido como "reforma constitucional en materia de derechos humanos". El Estado mexicano, en atención a lo anterior, intensificó su reconocimiento a tal cambio, ya que, como mandato constitucional, en armonía con el artículo 1 de la Constitución Política de los Estados Unidos Mexicanos, es su obligación el respeto, la promoción y la protección de los derechos humanos.

Tradicionalmente, la doctrina ha clasificado el derecho internacional de los derechos humanos en "generaciones". La primera generación corresponde a los derechos civiles y políticos; la segunda, a los económicos, sociales y culturales; la tercera, a los de solidaridad internacional (Hernández, 2015). Desde luego, no es una clasificación definitiva, universalmente asumida o válida; no obstante, a grandes rasgos es como podemos tener ese acercamiento a los derechos humanos.

Por lo que ve a los DESC, tampoco existe un criterio válido homogéneo para su clasificación, ya que, por ejemplo, hay quienes incluyen los derechos ambientales (derecho de tercera generación) en los DESC. Por otro lado, existen autores quienes asumen que los DESC son propiamente de segunda generación, pues surgieron a finales del siglo XIX, cuando se dio paso del llamado Estado liberal al benefactor. Justamente este último se caracterizó por implementar una línea de políticas públicas con enfoque social (Tello Moreno, 2011).

De manera muy general, podemos señalar que los derechos económicos, sociales y culturales "son los derechos humanos relacionados con el lugar de trabajo, la seguridad social, la vida en familia, la participación en la vida cultural y el acceso a la vivienda, la alimentación, el agua, la atención de la salud y la educación" (Oficina del Alto Comisionado de las Naciones Unidas para los Derechos Humanos, p. 3). 
Como podemos apreciar, en la definición que nos proporciona el Alto Comisionado de las Naciones Unidas para los Derechos Humanos, los DESC conllevan una línea claramente social y de acceso a servicios que el Estado debe proveer. Es así que tales derechos surgen como productores de movimientos sociales y respuestas para eliminar la desigualdad existente en la sociedad, la cual se manifiesta en la mala distribución de la riqueza y dificultades para acceder a trabajo, vivienda, o educación (Hernández, 2015).

Las principales fuentes de los DESC son la Declaración Universal de Derechos Humanos y el Pacto Internacional de Derechos Económicos, Sociales y Culturales. Es en estos documentos en los que recae la principal positivización de los DESC, así como el respaldo para exigir su cumplimiento a los Estados firmantes.

En torno a los DESC, por su naturaleza y composición, han existido impedimentos para demandar su debido cumplimiento a los Estados, ya que este tipo de derechos tiene su sostén en los presupuestos financieros públicos, en la voluntad política por parte tanto de gobernantes como de actores políticos y en su ejercicio, lo cual, desde nuestro punto de vista, no debería ser justificación para su ejecución o exigibilidad. Es en este rubro en el que encontramos un acercamiento para su demanda: protección no jurisdiccional, a través de los organismos públicos protectores de derechos humanos.

Pasaremos ahora al estudio de uno de los DESC, de manera más particular, en el sistema jurídico mexicano: el derecho a la vivienda. Una vez realizado lo anterior, podremos adentrarnos en el mecanismo no jurisdiccional de protección a tal derecho.

\section{EI derecho a la vivienda como un derecho humano}

Desde nuestra perspectiva, el derecho social lo podemos entender como un privilegio de unión social, para la integración de las personas menos favorecidas. En la normatividad mexicana, el derecho social se identifica con el derecho del trabajo, consagrado en el artículo 123 de la Constitución Política de los Estados Unidos Mexicanos (CPEUM). Asimismo, el artículo 27 de la Carta Magna tiene ese vínculo con el derecho social, ya que en él se vela por los derechos de los campesinos, por lo cual, el derecho del trabajo y el agrario son ramas del social. Y es que, en México, históricamente, los campesinos y los trabajadores han sido grupos vulnerables y se han encontrado en situaciones de exclusión. Luego, entonces, el objetivo del derecho social es que las diferencias entre diversas agrupaciones poblacionales disminuyan, con el aseguramiento del derecho a la salud, al vestido, a la educación, $\mathrm{y}$, desde luego, con el derecho a la vivienda, por mencionar algunos. 
Entendemos el derecho a la vivienda como "la prerrogativa de todo ser humano a habitar en una construcción digna, de manera estable, donde se lleve a cabo su vida privada" (Soberanes Fernández, 2019, p. 333). En nivel internacional, diversos instrumentos reconocen la importancia del derecho a la vivienda: el artículo 25.1 de la Declaración Universal de los Derechos Humanos y el artículo 11 del Pacto Internacional de Derechos Económicos, Sociales y Culturales. También se encuentra enumerado entre los Derechos del Niño, en el artículo 27 de la Convención; en el artículo 5 de la Convención Internacional sobre la Eliminación de todas las Formas de Discriminación Racial; en el artículo 14 de la Convención sobre la Eliminación de todas las Formas de Discriminación contra la Mujer; en el artículo 11 de la Declaración Americana de los Derechos y Deberes del Hombre, y en el artículo 8 de la Declaración sobre el Derecho al Desarrollo (Soberanes Fernández, 2019).

Estimamos, desde la óptica estrictamente formal, que el derecho a la vivienda se involucra en el cómo se tendrán que hacer las construcciones para tener una buena interacción humana, va de la mano del derecho urbanístico, de los usos de suelo, de los permisos de construcción, y de la regulación de asentamientos humanos, entre otras facetas. Empero, desde el ámbito social, ese derecho puede ser considerado inherente al individuo en su condición de trabajador, concebido como una prestación adicional al salario, por lo cual es una obligación constitucional.

Opinamos que el derecho a la vivienda se conjunta con otros derechos; cuando el primero se trasgrede, se ven violados otros (el de seguridad, libertad, dignidad, libre desarrollo, sano esparcimiento, por mencionar algunos).

Según apreciaciones del Comité de las Naciones Unidas de Derechos Económicos, Sociales y Culturales, para que una vivienda sea adecuada debe cumplir con criterios como la seguridad, disponibilidad de servicios, asequibilidad, habitabilidad, ubicación, entre otros. El derecho a una vivienda apropiada es humano y se encuentra integrado en las normas y leyes internacionales en las cuales se contemplan los demás derechos (lo toman como un conjunto para tener acceso a una vida conveniente con miras al desarrollo humano): la Declaración Universal de Derechos Humanos, el Pacto Internacional de Derechos Económicos, Sociales y Culturales y otros tantos acuerdos de los cuales México forma parte, por lo que no es un derecho que solo se contemple en la legislación mexicana (ONU-HABITAT, 2020).

Como se vio con anterioridad, el derecho a la vivienda adecuada se encuentra reconocido en el Pacto Internacional de Derechos Económicos, Sociales y Culturales (PIDESC) en su artículo 11. De esta manera, los gobiernos locales signatarios del pacto deben desarrollar políticas que garanticen este derecho, priorizando la 
atención de los grupos en situación de vulnerabilidad. Asimismo, el Informe de la Relatora Especial sobre una vivienda adecuada, como elemento integrante del derecho a un nivel de vida óptimo, y sobre el derecho de no discriminación establece: "la definición de la vivienda asequible debe tener en cuenta toda diferencia de ingresos y de acceso a los recursos financieros por razones de género, y dar oportunidad de asignación de las viviendas sociales o públicas a quienes no pueden hacer frente al costo de la vivienda" (Rolnik, 2011, p. 21).

En consecuencia, tenemos que existen ordenamientos internacionales, así como principios rectores, para tener un marco normativo que permita a la autoridad actuar efectivamente en la implementación de políticas públicas, las cuales garanticen una vivienda digna y acorde con una perspectiva de derechos humanos.

\section{El derecho humano a la vivienda en el Estado mexicano: el Instituto del Fondo Nacional de la Vivienda para los Trabajadores y el Fondo de la Vivienda del Instituto de Seguridad y Servicios Sociales de los Trabajadores del Estado}

A fin de estudiar el derecho a la vivienda como un bien humano en el Estado mexicano, expondremos brevemente una de las instituciones públicas que tiene la encomienda de proporcionar las condiciones jurídicas y financieras para que el domicilio sea más accesible a la población.

Al finalizar la Revolución mexicana, en 1917, cuando se promulgó la actual Constitución Política de los Estados Unidos Mexicanos, el Estado mexicano se vio en la necesidad de facilitar la vivienda a la población, ya que esta, debido a las consecuencias de los enfrentamientos históricos y a la reconstrucción general del país, no contaba con recursos económicos suficientes. En esa época, comenzó un importante flujo del campo hacia las grandes ciudades. Por ello, en los años 40 y 50, se empezaron a crear instituciones gubernamentales que se encargarían de promover el derecho a la vivienda y, de esta manera, se buscaba dar una respuesta a dicha problemática y necesidad.

En 1963, se creó el Programa Financiero de Vivienda; con él, el Estado mexicano empezó a darle un lugar importante al sector de vivienda social. El Gobierno federal constituyó, en el Banco de México, el Fondo de Operación y Financiamiento Bancario a la Vivienda (FOVI) como una institución promotora de la construcción y mejora de la vivienda de interés social, para otorgar créditos a través de la banca privada.

Actualmente, la Política Nacional de Vivienda del Gobierno Federal de México tiene como visión aumentar el flujo de efectivo, con miras a la adquisición de 
viviendas para los sectores de clase baja, por lo que busca incrementar estrategias de construcción que tengan una base sustentable. Tal política se rige, entonces, con planes definidos tendientes a declarar los bienes inmuebles en el Registro Público de la Propiedad, para darles una certeza jurídica y aumentar el valor del patrimonio. Así, se incentiva la mejora de la vivienda existente con remodelaciones internas y externas, con el fin de prolongar su durabilidad; del mismo modo, se dan más opciones de financiamiento para que el mayor número posible de personas acceda a ellas. Adicionalmente, se busca que cualquier espacio disponible sea apto para hacerlo habitable, por lo cual han existido grandes riesgos cuando ocurren movimientos tectónicos. También se intenta que se reactive el mercado de la vivienda, para que exista un mayor flujo de compra y venta (Sánchez Corral, 2020).

En México, desde 1972, existe una institución de carácter público, descentralizada, del Poder Ejecutivo, ofertante de la vivienda: el Instituto del Fondo Nacional de la Vivienda para los Trabajadores (INFONAVIT). De acuerdo con la normatividad aplicable, el objeto del INFONAVIT es establecer y operar un sistema de financiamiento que permita a los trabajadores obtener crédito barato y suficiente para la adquisición, en propiedad, de habitaciones cómodas e higiénicas; la construcción, reparación, ampliación o mejoramiento de habitaciones, y el pago de pasivos contraídos por los conceptos anteriores (artículo 3 de la Ley del Instituto del Fondo Nacional de la Vivienda para los Trabajadores).

El contexto en el que se desarrolló lo que ahora denominamos INFONAVIT comenzó en enero de 1943, cuando se promulgó la Ley del Seguro Social de 1943. Sin embargo, no es sino hasta 1972 que se crea la Ley del INFONAVIT, uno de los cuatro seguros sociales implementados por el Gobierno federal mexicano, junto con la Ley Federal de los Trabajadores, el Instituto de Seguridad y Servicios Sociales de los Trabajadores del Estado y el Instituto de Seguridad para las Fuerzas Armadas Mexicanas.

Al INFONAVIT se le dotó de personalidad jurídica, patrimonio propio, autarquía y la característica de ser a la par organismo fiscal autónomo con amplias facultades legales. Lo anterior, al considerarse, por razones prácticas, que las aportaciones patronales para el Fondo Nacional de Vivienda de los Trabajadores eran de seguridad social y, por ende, fiscales, soslayando el hecho de que tal ente público se encargaría de administrar las contribuciones patronales contempladas en el artículo 136 de la Ley Federal del Trabajo (Ruiz Moreno, 2014). Aunque ha sufrido reformas legales, el INFONAVIT continúa con la misión de satisfacer la necesidad de la vivienda para los trabajadores, desde los ángulos y perspectivas que las cambiantes condiciones del entorno y de la coyuntura del país le han demandado. A lo largo de su existencia, se pueden identificar al menos cuatro importantes etapas: 
1) Desde su fundación y hasta 1979, al participar en la construcción directa de casas de habitación para los trabajadores.

2) De 1980 a 1992, cuando financia los constructores de vivienda mediante un sistema de promociones.

3) De 1992 a 1995, cuando inicia la transición hacia una hipotecaria social, con base en la primera reforma a la Ley del INFONAVIT, al incorporarse el derecho de los trabajadores para escoger libremente su vivienda y el compromiso institucional de mantener, en términos reales, el valor de los ahorros individuales.

4) A partir de 1995, cuando se consolida el perfil financiero del Instituto, para contribuir a solucionar el rezago habitacional y brindar mayor protección al patrimonio de los derechohabientes, adecuando su orden normativo al nuevo sistema de pensiones del IMSS.

Históricamente, el INFONAVIT ha sido la corporación a la que se le ha encomendado la administración de los recursos destinados para la vivienda de los trabajadores. Cuida que tales herramientas sean accesibles en cuanto a pagos y que las viviendas cumplan con los estándares para el desarrollo óptimo de la persona.

Además del INFONAVIT, tenemos al Fondo de la Vivienda del Instituto de Seguridad y Servicios Sociales de los Trabajadores del Estado (FOVISSSTE), un órgano desconcentrado del Instituto de Seguridad y Servicios Sociales de los Trabajadores del Estado (ISSSTE), creado el 28 de diciembre de 1972. De acuerdo con los artículos 167, 168 y 169 de la Ley del Instituto de Seguridad y Servicios Sociales de los Trabajadores, el objetivo del FOVISSSTE es "establecer y operar un sistema de financiamiento que permita a los trabajadores obtener un crédito barato y suficiente, mediante préstamos con garantía hipotecaria" (Ley del ISSSTE).

Puntualizado el desarrollo sobre el INFONAVIT y el FOVISSSTE, pasaremos al estudio pormenorizado en el que estas autoridades son sujetas a revisión ante el organismo público de protección no jurisdiccional de derechos humanos competente: la Comisión Nacional de los Derechos Humanos.

\section{Protección no jurisdiccional del derecho humano a la vivienda}

Según el artículo 53 de la Ley del INFONAVIT, las instancias jurisdiccionales encargadas de dirimir las controversias entre los trabajadores y el INFONAVIT serán los tribunales federales en materia laboral. Los asuntos que se substanciarán en ellos versan sobre derecho a créditos, cuantía de aportaciones y descuentos o cualquier acto emitido por el Instituto que lesione los derechos de los trabajadores o de sus beneficiarios (artículo 52 de la Ley del INFONAVIT). Ahora bien, en esta 
parte ahondaremos en la protección no jurisdiccional del derecho humano a la vivienda, es decir, en aquellos trámites substanciados no ante los tribunales federales laborales, sino ante la Comisión Nacional de los Derechos Humanos (CNDH).

En México, cada estado de la federación cuenta con su propio organismo público de protección de derechos humanos, existen comisiones estatales, defensorías de derechos humanos o procuradurías. Estos tienen la encomienda de velar por la protección de los derechos humanos de la población en el nivel local, lo que significa investigar posibles violaciones a esos derechos por acciones u omisiones de autoridades locales, municipales o estatales. En lo federal, el organismo encargado de investigar posibles violaciones a derechos humanos por acciones $\mathrm{u}$ omisiones de autoridades federales es la Comisión Nacional de los Derechos Humanos. La competencia de la CNDH está determinada en el artículo 3 de la Ley de la Comisión Nacional de los Derechos Humanos: “...tendrá competencia en todo el territorio nacional, para conocer de quejas relacionadas con presuntas violaciones a los derechos humanos cuando éstas fueran imputadas a autoridades y servidores públicos de carácter federal...". El INFONAVIT es una autoridad de carácter federal; luego, entonces, las controversias que se susciten entre los trabajadores y el Instituto, en materia de derechos humanos, serán tramitadas ante la $\mathrm{CNDH}$.

Ahora bien, la CNDH tiene como facultades legales la emisión de "recomendaciones", es decir, resoluciones de carácter no vinculante ni obligatorio para las autoridades correspondientes. Las recomendaciones de la CNDH tienen criterios jurídicos, valoración de pruebas, hechos, razonamientos y argumentaciones de carácter técnico/jurídico; al final, se emiten observaciones que la autoridad debería seguir o atender. El carácter de las resoluciones de la CNDH es moral y ético. Aquí radica la diferencia con el sistema jurisdiccional propio del Poder Judicial, en el que las sentencias son de carácter obligatorio.

La CNDH, para su funcionamiento y tramitación de asuntos, en su estructura, cuenta con seis visitadurías. Cada una de estas tiene la encomienda de investigar quejas sobre derechos humanos, de acuerdo con alguna temática en particular, que pueden ir desde atención a migrantes, personas indígenas, personas en reclusión, personas con discapacidad, por mencionar algunas. A la Sexta Visitaduría, creada en el 2012, le corresponde conocer e investigar reclamos relacionados con posibles vulneraciones a los DESC, entre los que hemos citado el derecho a la vivienda. Es en dicha visitaduría en la que recae, principalmente, la investigación de las quejas en contra del INFONAVIT.

Empero, toda vez que el trabajo de la CNDH es interdisciplinar, la investigación de quejas en contra del INFONAVIT no es exclusiva de una visitaduría, sino que, 
dependiente del asunto y de las posibles aristas del análisis a las violaciones a los derechos humanos, es que cualquiera de las visitadurías generales puede investigar reclamos en contra del INFONAVIT. En este mismo sentido, habrá que precisar que no todas las quejas por vulneración al derecho a la vivienda son en contra del INFONAVIT, ya que, dentro del Estado mexicano, pueden existir diversas autoridades que por sus acciones $u$ omisiones pueden vulnerar este derecho.

De acuerdo con el oficio 10212, emitido como respuesta a la solicitud de información 3510000017120, en el periodo que comprende del 2015 al 2019, la CNDH reportó tener 1281 registros de quejas, de los cuales 65 expedientes fueron considerados como reclamos por presuntas violaciones a los derechos humanos.

En el 2013, se presentó ante la CNDH una queja, en la cual los agraviados manifestaron la falta de solución al problema planteado desde el 2006, sobre los daños estructurales que habían ocurrido en las estructuras de las edificaciones en la "Unidad Habitacional SCT Vallejo", ubicada al norte de la ciudad de México, capital de la nación. El hecho dio origen al expediente CNDH/4/2013/1750/Q. Con motivo de las investigaciones, la CNDH emitió la Recomendación 76/2013. Por parte del organismo nacional, se documentaron desplomos generados por hundimientos diferenciales, situación de la cual los afectados no obtuvieron respuesta alguna (por parte del FOVISSSTE) ${ }^{3}$.

Después de diversos dictámenes e investigaciones al respecto, la CNDH consideró que el FOVISSSTE vulneró los derechos a la vivienda digna, la legalidad y la seguridad jurídica, consagrados en los artículos 1 (párrafos primero, segundo y tercero), 8 y 35 (fracción V), de la Constitución Política de los Estados Unidos Mexicanos.

La CNDH, en ejercicio de las facultades que la ley le otorga, como medidas de protección desprendidas de la Recomendación 76/2013, solicitó que los casos de las personas agraviadas fueran remitidos al Grupo de Trabajo de Atención a Acreditados de la Comisión Ejecutiva del Fondo de la Vivienda del ISSSTE, para que analizara y atendiera, de manera congruente, fundada y motivada, la solicitud que formularon las víctimas (Comisión Nacional de los Derechos Humanos, 2020).

Una de las recomendaciones más específicas de la CNDH sobre la protección del derecho a la vivienda es la 38/2018, acerca de las personas damnificadas por el huracán "Ingrid", y la tormenta tropical "Manuel", en el municipio de Acapulco

3 El Fondo de la Vivienda del Instituto de Seguridad y Servicios Sociales de los Trabajadores (FOVISSSTE), es un organismo que otorga créditos hipotecarios a personas que sean trabajadoras de una institución pública de carácter federal.

$12 \begin{aligned} & \text { Revista Latinoamericana de Derechos Humanos } \\ & \text { Volumen } 32 \text { (1), I Semestre 2021 } \\ & \text { ISSN: 1659-4304 • EISSN: 2215-4221 }\end{aligned}$ 
de Juárez, en Guerrero, estado ubicado al sur de México (Comisión Nacional de los Derechos Humanos, 2020).

Entre el 13 y el 16 de septiembre del 2016, el huracán "Ingrid", categoría 1, entró por el golfo de México y la tormenta tropical "Manuel", por la costa de Pacífico, afectando a gran parte del territorio mexicano. Uno de los estados de la República Mexicana con más daños causados fue el de Guerrero, principalmente el municipio de Acapulco. Debido a dichas afectaciones, el Gobierno federal tuvo a bien emitir la "Declaratoria de Desastre Natural por la ocurrencia de lluvia severa del 14 de septiembre de 2013, en 56 municipios del Estado de Guerrero"4; lo anterior, a fin de lograr acceder a los recursos federales del Fondo de Desastres Naturales. Como consecuencia de esa Declaratoria de Desastres Naturales, el Gobierno federal determinó destinar los recursos a la Secretaría de Desarrollo Agrario, Territorial y Urbano, para atender las zonas perjudicadas por el huracán y la tormenta tropical.

De acuerdo con lo señalado por la CNDH en la Recomendación 38/2018, el 8 de abril del 2014, la SEDATU y una empresa "celebraron un contrato de obra pública con el objeto de construir viviendas consistentes en 330 acciones parciales, 357 acciones totales y 137 acciones de reubicación" (Comisión Nacional de los Derechos Humanos, 2020, p. 3), sin embargo, en fecha 15 de agosto de 2016, la SEDATU dio a conocer que la empresa había incumplido con su obligación contractual. Ello dio lugar a que el 28 de abril del 2017 se presentara una queja ante la Comisión Nacional, en la cual se hicieron diversas manifestaciones sobre violaciones a los derechos humanos de las personas damnificadas por el huracán "Ingrid" y la tormenta tropical "Manuel", toda vez que las viviendas no les fueron entregadas.

$\mathrm{La} \mathrm{CNDH}$, de acuerdo con sus investigaciones y documentales allegados, encontró elementos que acreditaron una afectación al derecho humano a la vivienda, puesto que la autoridad responsable incumplió sus "obligaciones de disponibilidad de servicios, materiales, facilidades e infraestructura, habitabilidad y asequibilidad sobre el derecho a una vivienda adecuada, afectaciones a los derechos de la niñez y adolescencia de la comunidad 'La Isla las Casitas', la responsabilidad Institucional y la reparación integral del daño" (Comisión Nacional de los Derechos Humanos, 2020, p. 11). Es capital precisar que la CNDH consideró que el Gobierno federal, a través de la SEDATU, vulneró el derecho humano a la vivienda, primordialmente por omisión, al no haber supervisado el actuar de la empresa encargada de realizar las casas para los afectados en el municipio de Guerrero; es decir, tal Gobierno, en

4 La "Declaratoria de Desastre Natural" es una medida emergente que implementa el Gobierno federal ante desastres provocados por cuestiones naturales, con el objetivo de proporcionar recursos para la reconstrucción tras los daños generados por los desastres naturales referidos. 
aras de velar por la protección de los derechos humanos, debe realizar una vigilancia adecuada cuando contrate empresas, para cumplir con un determinado objetivo.

Por lo anterior, la SEDATU, al no haber realizado, con el debido cuidado y estricta observancia, la supervisión de la empresa originó que terceros, en este caso entes privados o actores no estatales, ocasionaran violaciones al derecho a la vivienda de un grupo en situación en vulnerabilidad, determinado: la población afectada por desastres naturales en el municipio de Acapulco.

La CNDH, como medida de protección, solicitó a las autoridades responsables que las personas agraviadas pudieran acceder al servicio de construcción de las viviendas afectadas y así entregarles las casas con escrituras públicas.

Si bien el INFONAVIT y el FOVISSSTE son las principales autoridades que por mandato de ley tienen la obligación de promover y respetar, principalmente, el derecho humano a la vivienda y como derivación de sus omisiones o acciones incurren en violaciones a los derechos humanos en general, habrá que precisar que existen también otras autoridades que, por los mismos motivos, violan el derecho en cuestión. En la última parte de este apartado, veremos el caso concreto de dos recomendaciones realizadas por la CNDH a diversas autoridades de orden federal, estatal y municipal, donde se acreditaron violaciones al derecho humano a la vivienda.

Como primer caso, tenemos que en el expediente CNDH/6/2015/1603/Q y en su acumulado CNDH/6/2015/2656/Q, la CNDH se llenó de evidencias y documentales para determinar que las siguientes autoridades violaron el derecho humano a la vivienda:

1) Secretario de Medio Ambiente y Recursos Naturales

2) Procuradora Federal de Protección al Ambiente

3) Gobernador Constitucional del Estado de Chihuahua

4) Ayuntamiento de Chihuahua

De acuerdo con las investigaciones realizadas por la $\mathrm{CNDH}$, en lo concerniente al derecho a la vivienda, se acreditó que la dispersión y exposición a elementos nocivos originados por residuos minero-metalúrgicos, en la Planta Ávalos, desencadenaron condiciones desfavorables que afectan la salud y el libre desarrollo, así como la calidad de vida de las personas residentes cerca de esa planta. La CNDH esbozó que el derecho humano a la vivienda se vio vulnerado cuando las autoridades contravinieron lo señalado por el Comité de Derechos Económicos, Sociales y Culturales, en su observación general 4 , párrafo 8 , inciso f), la cual señala que el acceso 
a la vivienda no debe localizarse en espacios "contaminados ni en la proximidad inmediata de fuentes de contaminación que amenazan el derecho a la salud de los habitantes". Con ello, podemos apreciar que el derecho humano a la vivienda se vio afectado por encontrarse interrelacionado con otro fundamental: el derecho a la salud. Producto de las acciones y omisiones de las autoridades, las violaciones al derecho humano a la vivienda dieron lugar a la Recomendación 91/2019 (Comisión Nacional de los Derechos Humanos, 2020). En este caso particular, tales transgresiones, la CNDH sugirió a las autoridades, además de todas las acciones necesarias en materia de daño ambiental y salud de las personas, que se llevara a cabo una estrategia para la reubicación de los afectados por el mal manejo de los residuos de origen minero responsabilidad de la Planta Ávalos. De esta manera, en materia del derecho humano a la vivienda, se insta directamente una morada adecuada y digna, donde no se tenga el riesgo de padecer afectaciones en la salud.

El segundo caso que tenemos es el que proviene de la Recomendación 20/2019. Esta nació al quebrantarse el derecho humano a la integridad personal y a la vivienda "por la falta de debida diligencia en el mantenimiento de distancias seguras y protecciones adecuadas en las líneas aéreas de media tensión, que derivó en lesiones por quemaduras en un domicilio en la Ciudad de México" (Comisión Nacional de los Derechos Humanos, 2020, p. 1).

La CNDH consideró que la autoridad encargada de proveer y administrar los servicios de luz eléctrica, la Comisión Federal de Electricidad (CFE), no cumplió con lo señalado en la NOM-001- SEDE-2012, la cual constituye el hilo normativo rector en materia de instalaciones eléctricas en México. La Comisión señaló que la CFE no efectuó a cabalidad la supervisión que garantizara distancias seguras y adecuadas entre el cableado de media tensión y las viviendas de los agraviados, lo que ocasionó poner en riesgo la integridad física de los habitantes.

Como recomendación, se conminó a la CFE a realizar los trámites respectivos, a fin de garantizar la reparación del daño a las personas que sufrieron lesiones físicas. De igual manera, se le solicitó a la autoridad responsable un dictamen en materia de electricidad y cableado, para certificar que no se volvería a exponer a las personas, al estar sus viviendas en una distancia inadecuada del cableado eléctrico; esto considerando lo señalado en las especificaciones técnicas de separaciones horizontales y verticales previstas en la NOM-001- SEDE-2012. Es de suma importancia asentar que el derecho humano a la vivienda no se restringe únicamente a la accesibilidad de aquella; es decir, la edificación no solo debe ser accesible, sino también adecuada y habitable, cumplir con las condiciones normativas y físicas para el libre desarrollo de la persona. En esta recomendación, la 
CNDH visibilizó las consecuencias de una construcción que, si bien es accesible, no era del todo habitable y adecuada.

Según lo previo, podemos señalar determinadas acciones u omisiones de la autoridad responsable, contrarias al derecho a la vivienda: la falta de infraestructura necesaria para brindar los apoyos, con el objetivo de satisfacer el disfrute de este derecho; obstaculizar el acceso a los servicios que el Estado presta para proporcionar la vivienda; omitir dar cumplimiento a las políticas financieras estatales, que permitan obtener un crédito favorable para la adquisición de una vivienda, y complicar el pago de créditos hipotecarios (Soberanes Fernández, 2019, p. 335).

En términos generales, de acuerdo con el oficio 10212 emitido por la CNDH, no solo el INFONAVIT o el FOVISSSTE tuvieron quejas por violaciones al derecho humano a la vivienda. A continuación, enlistamos todas las autoridades federales, estatales y municipales con reclamos en materia de derecho a la vivienda, registradas por la CNDH en el periodo 2015-2019:

Ayuntamiento de Ecatepec de Morelos, estado de México

- $\quad$ Secretaria de Comunicaciones y Transportes

- Gobernador Constitucional del Estado de Colima

- $\quad$ Ayuntamiento de Colima, Colima

- Instituto Mexicano del Seguro Social

- $\quad$ Procuraduría General de Justicia del Estado de Colima

- Secretaria del Trabajo y Previsión Social

- $\quad$ Comisión Federal de Electricidad

- Comisión Nacional del Agua

- $\quad$ Gobernador Constitucional del Estado de Coahuila

- Gobernador Constitucional del Estado de Durango

- Ayuntamiento de Gómez Palacio, Durango

- Ayuntamiento de Torreón, Coahuila

- Secretaria de Medio Ambiente y Recursos Naturales

- $\quad$ Secretaria de Salud

- Gobernador Constitucional del Estado de Chiapas

- $\quad$ Ayuntamiento de Tuxtla Gutiérrez, Chiapas 
- Comisión Nacional para el Desarrollo de los Pueblos Indígenas

- Secretaria de Desarrollo Agrario, Territorial y Urbano

- Fideicomiso Fondo Nacional de Habitaciones Populares

- $\quad$ Secretaria de la Defensa Nacional

- $\quad$ Secretaria de Marina

Como podemos apreciar, las violaciones al derecho humano a la vivienda en México, si bien recaen, propiamente, en las dos principales autoridades a las que hemos venido haciendo referencia, existen elementos para considerar que hay participación de otras autoridades, de orden federal, estatal y municipal, a la hora de realizar las investigaciones que determinar las violaciones a tal derecho.

\section{Conclusiones}

Como en cualquier investigación, siempre quedarán muchos elementos pendientes de estudiar. Por la naturaleza del presente trabajo, no es posible abordar, en su totalidad, lo complejo del derecho a la vivienda y todas las afectaciones, por el accionar o la omisión de cada una de las autoridades federales, estatales y municipales, enlistadas en párrafos anteriores. Sin embargo, consideramos que las generalidades abordadas servirán como base legislativa para volver la mirada al derecho a la vivienda y hacer de este un bien que en verdad sea accesible, adecuado y digno en la realidad, no solo en el nivel normativo.

Otro tema de suma importancia, derivado del derecho a la vivienda y pendiente de examen, es el análisis de los programas de financiamiento hipotecario, que en México han jugado un papel esencial en el proceso de impulsar el crecimiento de la industria de la vivienda, así como la disponibilidad financiera en un mercado con base en créditos monetarios. Además, la flexibilidad de los programas en cuanto a topes de valor de la vivienda, los cofinanciamientos, destinos de crédito, mecanismos de acceso y calificación al crédito han permitido el crecimiento del sector de vivienda.

Nuestro objetivo, en la indagación, siempre fue esbozar qué debemos entender por vivienda digna, no únicamente como un concepto abstracto o filosófico, sino como una realidad que impacta en lo material y va desde condiciones ambientales hasta situaciones no tan perceptibles (como un cableado eléctrico). 
Asimismo, nos interesó desarrollar cómo han sido los procesos en los cuales el Gobierno federal ha realizado acciones $\mathrm{u}$ omisiones que confluyeron en violaciones al derecho a la vivienda.

El Estado debe garantizar, mediante mecanismos legales y políticas públicas sociales, la regularización de las actividades de las desarrolladoras inmobiliarias, encargadas de la construcción y venta de las viviendas, para que su actuar no interfiera con el libre ejercicio del derecho humano a la vivienda de los trabajadores en general. Esto nos obliga a pensar cuáles son las responsabilidades de todos los actores involucrados en la composición del derecho humano a la vivienda (Estado, capital, trabajador).

Como trabajo pendiente, se torna trascendental que el Estado replantee cuál es la relación entre vivienda y ciudad, es decir, cuáles son las necesidades de la primera y las exigencias de la segunda (cosmopolita contemporánea), donde la multiculturalidad es ya un factor básico para la convivencia en sociedad. Igualmente, creemos esencial retomar, en futuras investigaciones, el aspecto social propio de la vivienda: ¿qué significa hoy hacer vivienda social en México?, ¿cuál es propiamente el interés social de la vivienda?

Entre mayor sea el abundamiento, hacen falta más estudios a profundidad y técnicos en relación con la vivienda como un derecho humano, así como de su efectividad. Un análisis que se vuelve indispensable tendría que ver con las posibilidades de los trabajadores para acceder a los créditos o financiamientos que otorga el INFONAVIT, así como con los procesos de asignación. Lo anterior deviene en investigaciones sumamente técnicas, que involucran perspectivas económicas, estadísticas y presupuestarias. Examinar el poder adquisitivo del trabajador, sus ingresos y los intereses al capital son elementos que escapan, en un primer momento, a la labor que en este momento se realiza; sin embargo, es conveniente que en trabajos posteriores se incorpore el estudio económico sobre el acceso a los financiamientos y cómo poder implementar mecanismos efectivos que no vulneren la economía familiar, pero que proporcionen posibilidades reales para tener un vivienda digna y adecuada.

Como hemos podido advertir, la Ley del Instituto del Fondo Nacional de la Vivienda para los Trabajadores no contempla, explícitamente, los criterios para considerar una vivienda digna o adecuada, en virtud de que dichos términos no son propiamente jurídicos, sino que implican cuestiones éticas, sociológicas, demográficas o, incluso, de carácter estructural y arquitectónico. 
Finalmente, desde nuestra óptica, es menester no solo un marco jurídico aplicable sobre el derecho a la vivienda, sino de toda una estructura política para regular las desarrolladoras inmobiliarias y establecer así las directrices con miras a que la vivienda sea, en efecto, digna y adecuada, en armonía con una visión de derechos humanos.

\section{Referencias}

Acción Ciudadana Frente a la Pobreza. (2017). Derechos humanos y pobreza. Politicas públicas frente a la pobreza con la perspectiva de derechos del artículo 1 constitucional. México: CNDH.

Coello, U. (24 de 11 de 2020). UNACH Virtual. https://www.cv.unach.mx/uvfile/uv/ldh/ $\mathrm{m} 5 /$ jurisdiccionales/sub1/reconocimiento_s1ai.pdf

Comisión Nacional de los Derechos Humanos. (24 de 11 de 2020). https://www.cndh. org.mx/. https://www.cndh.org.mx/sites/default/files/doc/Recomendaciones/2013/ REC_2013_076.pdf

Comisión Nacional de los Derechos Humanos. (24 de 11 de 2020). https://www.cndh. org.mx/. https://www.cndh.org.mx/sites/default/files/doc/Recomendaciones/2018/ Rec_2018_038.pdf

Comisión Nacional de los Derechos Humanos. (24 de 11 de 2020). https://www.cndh.org. $m x /$ https://www.cndh.org.mx/sites/default/files/documentos/2019-11/Rec_2019_091.pdf

Comisión Nacional de los Derechos Humanos. (24 de 11 de 2020). https://www.cndh.org. $m x /$. https://www.cndh.org.mx/sites/default/files/documentos/2019-05/Rec_2019_020. pdf

Galiana, Á. (2017). La vivienda como objeto de estudio desde el derecho: la vivienda como derecho humano y la cátedra UNESCO sobre vivienda. Habitat y Sociedad, 129-144.

García, A. (2015). Los derechos económicos, sociales, culturales y ambientales (DESCA) como derechos exigibles en el nuevo constitucionalismo latinoamericano. México: CNDH.

Gómez, C., Sánchez, M., \& Torres, Ó. (2017). Ciudades Sostenibles y Derechos Humanos. México: CNDH-UNAM.

Hernández, A. (2015). Los derechos económicos, sociales, culturales y ambientales en el nuevo modelo constitucional de derechos humanos en México. México: CNDH.

Herrera, M. (2003). Manual de Derechos Humanos. México: Porrúa. 
Hidalgo, A. (2006). Los derechos humanos. Protección de grupos discapacitados. México: Porrúa.

Oficina del Alto Comisionado de las Naciones Unidas para los Derechos Humanos. (s.f.). Preguntas frecuentes sobre los Derechos Económicos, Sociales y Culturales. ONU.

ONU-HABITAT. (04 de 02 de 2020). Alto Comisionado de los Derechos Humanos. https:// www.ohchr.org/Documents/Publications/FS21_rev_1_Housing_sp.pdf

Quintana, C. (1998). Derechos Humanos. México: Porrúa.

Ríos, M. (1996). Introducción al Estudio de los Derechos Humanos. México: CIGRO.

Rodríguez, A. (2011). Origen, evolución y positivización de los derechos humanos. México: CNDH.

Rolnik, R. (2011). Informe de la Relatora Especial sobre una vivienda adecuada como elemento integrante del derecho a un nivel de vida adecuado y sobre el derecho no discriminación a este respecto. New York: Consejo de Derecho Humanos-ONU.

Ruiz, Á. G. (2014). Nuevo Derecho de la Seguridad Social. México: Porrúa.

Sánchez, J. (24 de 11 de 2020). http://conurbamx.com/home/. http://conurbamx.com/home/ wp-content/uploads/2015/05/libro-vivienda-social.pdf

Soberanes, J. L. (2019). Hechos violatorios de los derechos humanos. Manual para su calificación. México: Porrúa-CNDH.

Tello Moreno, L. F. (2011). Panorama general de los DESCA en el Derecho Internacional de los Derechos Humanos. México: CNDH.

Vázquez, D. (2015). Los derechos económicos y sociales en latinoamérica: ¿la idelogía importa? México: CNDH. 